\title{
Challenges in enriching milk fat with polyunsaturated fatty acids
}

\author{
Jennifer Stamey Lanier ${ }^{1}$ and Benjamin A. Corl ${ }^{2^{*}}$
}

\begin{abstract}
Milk fatty acid composition is determined by several factors including diet. The milk fatty acid profile of dairy cows is low in polyunsaturated fatty acids, especially those of the n-3 series. Efforts to change and influence fatty acid profile with longer chain polyunsaturated fatty acids have proven challenging. Several barriers prevent easy transfer of dietary polyunsaturated fatty acids to milk fat including rumen biohydrogenation and fatty acid esterification. The potential for cellular uptake and differences in fatty acid incorporation into milk fat might also have an effect, though this has received less research effort. Given physiological impediments to enriching milk fat with polyunsaturated fatty acids, manipulating the genome of the cow might provide a greater increase than diet alone, but this too may be challenged by the physiology of the cow.
\end{abstract}

Keywords: Dairy cow, Milk fat, Polyunsaturated fatty acids

\section{Introduction}

Concentrations of milk components determine the value of milk produced. Non-nutritional factors like parity, season, genetics, stage of lactation, and mastitis are known to influence milk composition. Milk fat is the most variable and energy dense component of milk and is easily influenced by nutrition, followed by protein and lactose, respectively, which remain relatively stable [1]. Plant and marine oils, feeding strategy, dietary fiber, concentrate inclusion, and ionophores are known to alter milk fat content and composition. Even though intense genetic selection for milk yield decreases milk fat content, there is minimal effect of selection for milk yield on milk fatty acid profile [2, 3].

The ability to change milk composition allows for improved processing characteristics, enhanced nutrient composition, and delivery of nutraceuticals for human health. Increasing the level of polyunsaturated fatty acids is the goal of nutritional modulation of milk fat synthesis, whether for a physical characteristic, such as improving the spreadability of butter, or a nutritional benefit, like decreased milk fat content or enhanced polyunsaturated fatty acids concentration [1, 4]. Human health benefits associated with consuming n-3 fatty acids encourage

\footnotetext{
* Correspondence: bcorl@vt.edu

2Department of Dairy Science, Virginia Tech, Blacksburg, VA 24061-0315, USA Full list of author information is available at the end of the article
}

development of functional foods for humans. Consumer perceptions of milk fat composition and quality may be improved by dietary supplements that increase milk fat content of n-3 fatty acids [4]; however, markedly increasing milk fat polyunsaturated fatty acid content has proved difficult.

\section{Ruminal biohydrogenation}

Based on the diet of the cow, milk should be rich in polyunsaturated fatty acids. The diet of a lactating dairy cow typically contains $4-6 \%$ fat and is enriched in polyunsaturated fatty acids [5]. The glycolipids and phospholipids found in forages are rich in linolenic (cis-9, cis-12, cis-15 18:3) and linoleic acids (cis-9, cis-12 18:2). In contrast, the lipids of seed oils found in concentrates, such as corn or soybeans, are predominantly triglycerides containing linoleic acid and oleic acid (cis-9 18:1); however, efforts in plant breeding have been made to change the fatty acid profile of seed oils to alter the relative proportions of saturated, monounsaturated, and polyunsaturated fatty acids [6,7]. Although lipids are found in small amounts in ruminant feedstuffs, the fatty acids are largely unsaturated.

Despite significant amounts of polyunsaturated fatty acids entering the rumen, outflows of polyunsaturated fatty acids into the small intestine are limited. The major fatty acid entering the small intestine is stearic acid. 
Smaller quantities of unsaturated fatty acids, many containing trans double bonds are also found entering the small intestine [8]. This change in fatty acid profile from consumption to absorption has been repeatedly observed [9-11]. Significant quantities of dietary polyunsaturated fatty acids were converted to more saturated fatty acids prior to the small intestine due to rumen biohydrogenation.

Ester linkages in feed lipids are hydrolyzed by microbial lipases, and lipolysis is a prerequisite for biohydrogenation of dietary unsaturated fatty acids [12]. Bacteria that biohydrogenate dietary lipids act on free fatty acids, not esterified fatty acids $[13,14]$. Several bacterial species are known to hydrolyze fatty acid ester linkages, and a full complement of lipases capable of hydrolyzing dietary lipids are found among rumen bacteria [15-17].

A range of diverse rumen bacteria have been isolated that have the capacity to biohydrogenate unsaturated fatty acids with the protozoa appearing to be of less importance (see review by [18]). The biohydrogenation of unsaturated fatty acids involves several biochemical steps. Polan et al. [19] were among the first to propose that different populations of bacteria were necessary for the complete hydrogenation of polyunsaturated fatty acids. Kemp and Lander [20] divided the bacteria into two groups based on the reactions and end-products of biohydrogenation. Group A bacteria hydrogenate linoleic and linolenic acid only as far as trans-11 18:1. The second population, Group B bacteria, is capable of hydrogenating monounsaturated fatty acids and linoleic acid completely to stearic acid. Without group B bacteria, a complete hydrogenation of polyunsaturated fatty acids is not possible [20]. An alternative description of biohydrogenating bacteria based on their correct taxonomy has been proposed by Lourenço et al. [21].

The sequence of the biohydrogenation of linoleic acid and linolenic acid is presented in Fig. 1. The initial biohydrogenation step of fatty acids containing a cis-9, cis12 double bond system is the isomerization of the cis-12 double bond by linoleate isomerase (EC 5.2.1.5). The isomerase has been partially purified and kinetic properties characterized in a limited number of bacterial species [14, 20, 22, 23]. In the biohydrogenation of linoleic acid, the second reaction is a reduction resulting in conversion of CLA to trans-11 18:1 followed by hydrogenation to stearic acid (Fig. 1). Similar to linoleic acid, biohydrogenation of linolenic acid begins with an isomerization followed by a sequence of hydrogenations, and terminates with formation of stearic acid. As biohydrogenation reduces unsaturated fatty acid availability for absorption, feeding dairy cows with polyunsaturated fatty acid-rich feeds, including fresh grasses, does not easily increase the quantities of these fatty acids in milk fat of dairy cows.

Supplementing the diet of dairy cows with oils and full-fat oilseeds containing unsaturated fatty acids can increase milk fat concentrations of polyunsaturated fatty acids [1], but this is not without risks. Supplementing polyunsaturated fatty acids to the diet increases the potential for a shift in biohydrogenation pathways that results in the production of biohydrogenation intermediates of linoleic acid that are known to cause milk fat depression (Fig. 1) and pathways of linolenic acid biohydrogenation

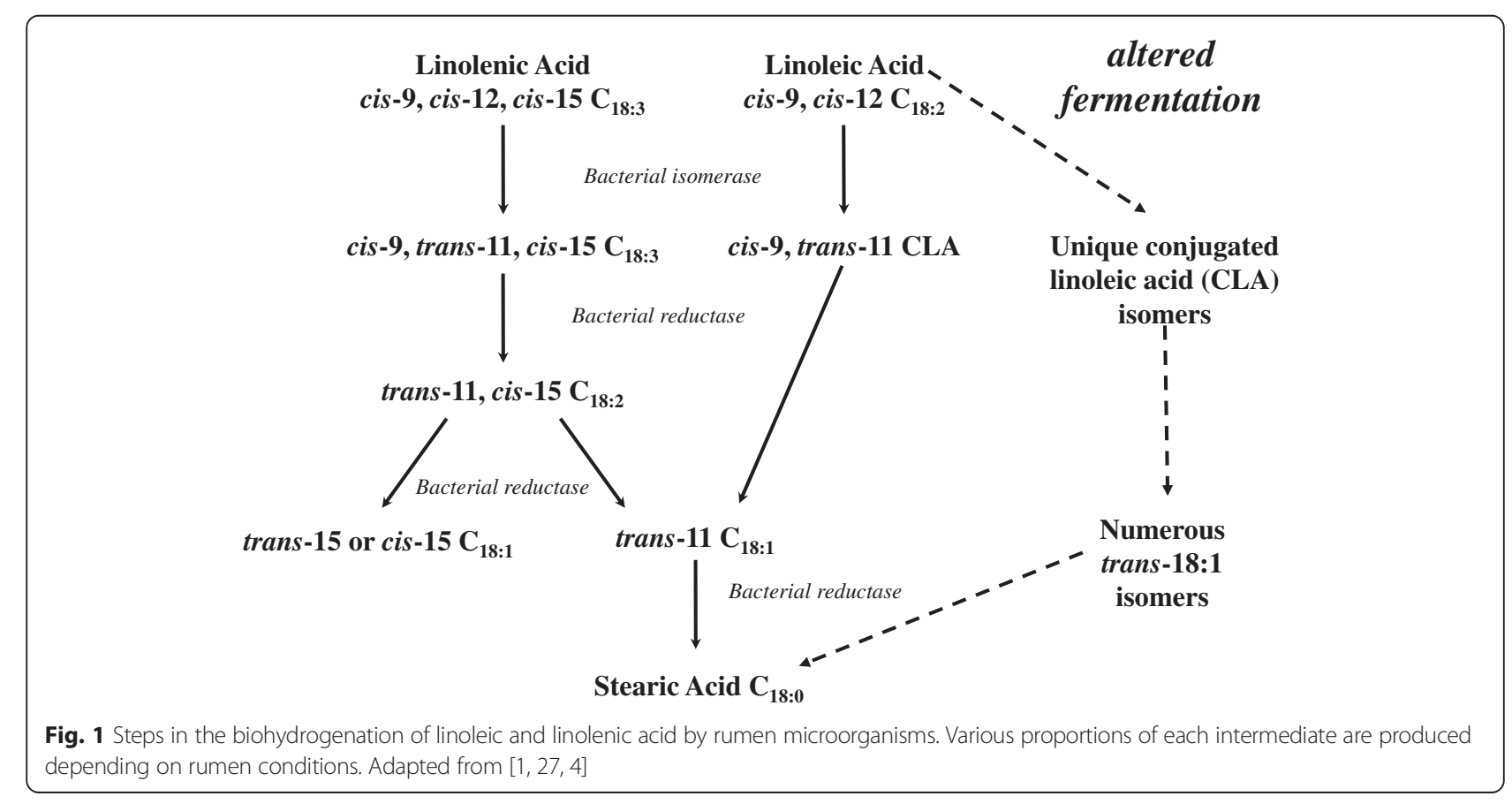


are also likely to be affected. A variety of diets are known to cause changes in milk fat composition and low milk fat yields, but are typically categorized as diets high in readily digestible carbohydrates and low in effective fiber (high grain/low forage) and supplemented with polyunsaturated fatty acids [24, 25]. These diets modify the rumen environment initiating altered pathways of biohydrogenation and increased rumen outflow of transisomers. The level of milk fat reduction can be greater than $50 \%$ without changes in milk protein or lactose concentrations [26].

The biohydrogenation theory of milk fat depression proposes that the production of trans-intermediates of altered rumen biohydrogenation pathways negatively impact synthesis of milk fat in the mammary gland [26]. Conjugated linoleic acids are octadecadienoic acids with conjugated double bonds and are primarily found in ruminant fats as a result of linoleic acid biohydrogenation [27]. While conjugated linoleic acids are purported to have numerous biological effects, the trans-10, cis-12 isomer is a potent inhibitor of milk fat synthesis [28]. Peterson et al. [29] demonstrated a curvilinear relationship between the dosage and milk fat yield of trans-10, cis-12 conjugated linoleic acid and the reduction in milk fat yield. The relationship exists between trans-10, cis-12 conjugated linoleic acid and milk fat yield in dietinduced milk fat depression as well. Lock et al. [30] examined trans-10 18:1, a downstream intermediate of trans-10, cis-12 conjugated linoleic acid biohydrogenation, for its potential as an additional fatty acid inhibiting milk fat synthesis. In this experiment, $42.6 \mathrm{~g} / \mathrm{d}$ trans-10 18:1 was compared with $4.3 \mathrm{~g} / \mathrm{d}$ trans-10, cis12 conjugated linoleic acid, and fatty acids were infused for 4 days. No reduction in milk fat was observed with the trans-10 18:1 treatment. Authors concluded that trans-10 18:1 was a marker of altered biohydrogenation and did not appear to have a role in inhibition milk fat synthesis [30].

The presence of docosahexaenoic acid (cis-4, cis-7, cis10, cis-13, cis-16, cis-19 22:6) in polyunsaturated fatty acids supplements can influence rumen biohydrogenation of dietary fatty acids. Klein and Jenkins [31] demonstrated that docosahexaenoic acid itself is not converted to trans-11 18:1, but modifies biohydrogenation of other long-chain polyunsaturated fatty acids present in the rumen, such as linoleic and linolenic acids. Docosahexaenoic acid promotes accumulation of vaccenic acid (trans-11 18:1) during linoleic acid biohydrogenation, but the presence of other fatty acids in polyunsaturated fatty acids supplements interact with dietary linoleic acid to increase trans-10, cis-12 conjugated linoleic acid production [32-34]. Rumen protection can circumvent interacting factors that influence biohydrogenation and prevent milk fat depression.

\section{Rumen protection of polyunsaturated fatty acids from biohydrogenation}

Increasing the post-ruminal absorption of polyunsaturated fatty acids might have implications for improving dairy cow reproduction as described by Santos et al. [35] in their review of the effects and benefits of long chain fatty acids on reproduction. For cows, n-3 fatty acid supplements have been purported to improve reproductive efficiency of dairy cattle. N-3 polyunsaturated fatty acids inhibit prostaglandin- $\mathrm{F}_{2 \alpha}$ synthesis through competition with arachadonic acid as a precursor for prostaglandin synthesis [36-38]. In some studies, feeding n-3 fatty acids to cows reduced prostaglandin secretion and improved fertility and embryo survival [35].

Rumen protection increases polyunsaturated fatty acid flow to the duodenum and absorption by the intestines without impacting fermentation [39]. Technologies promising protection from biohydrogenation include coating polyunsaturated fatty acids with formaldehyde-treated casein, lipid encapsulation, or structural change using calcium salts and fatty acids amides to resist microbial enzymes [39]. Whole oilseeds and calcium salts of fatty acids provide consistent duodenal flows, but do not provide a protected source of $n-3$ polyunsaturated fatty acids [40]. Lipid encapsulation is a method that may allow n-3 polyunsaturated fatty acids to remain protected in the rumen, avoid biohydrogenation, and be available for absorption and utilization [41, 42]. Rumen-protected fat sources that deliver consistent duodenal flows of $n-3$ polyunsaturated fatty acids remain to be elucidated and commercially developed.

\section{Lipid absorption and secretion by the intestine}

The absorption of long-chain fatty acids has been extensively reviewed [43-45]. Long-chain fatty acids reach the intestine largely as saturated free fatty acids affixed to the surface of feed particles and bacteria, or as components of microbial phospholipids and sterol esters [8]. Protected fatty acids delivered to the small intestine as intact triglycerides are digested by pancreatic lipase and colipase as they are in simple stomached animals, releasing free fatty acids and monoacylglycerols [44]. Bile salts secreted in the duodenum separate fatty acids from particles by their detergent action, forming micelles via lysolecithin produced by phospholipase $\mathrm{A}_{2}$. These components are absorbed by diffusion when the micelle moves across the unstirred water layer of the intestinal epithelium [8]. Fatty acid digestibility may decline with increased fatty acid intake as micelle formation becomes limiting [44].

In the enterocyte, long-chain fatty acids are esterified to form cholesterol esters, phospholipids, and triglycerides. Micelles form containing a triglyceride and cholesterol ester core with a surface monolayer of phospholipids 
and unesterified cholesterol. Apolipoproteins A and B (characteristically Apo B48; [44]), made in the intestine, are complexed with these lipids into very low-density lipoproteins and secreted into lymph, entering the bloodstream at the thoracic duct [46-48]. Other apolipoproteins are synthesized in the liver and transferred from high density lipoproteins in circulation. Apo CI to CIV are cofactors for lipoprotein lipase and Apo $\mathrm{E}$ is required for liver uptake; allowing lipoproteins to control lipid utilization in energy metabolism [44]. Chylomicrons are the largest and least dense $(<0.95 \mathrm{~g} / \mathrm{mL})$ of the lipoproteins and are secreted by the enterocyte following a meal; however, very low-density lipoprotein $(0.95-1.006 \mathrm{~g} / \mathrm{mL})$ secretion is predominant in ruminants due to the low fat content of their diets [44, 49].

Though triglycerides are the major lipid class found in lymph of simple stomached animals, the proportion of phospholipids to triglycerides is higher in ruminants [44]. Increased dietary fat or rumen outflow of polyunsaturated fatty acids increases chylomicron secretion, but the triglyceride proportion remains unchanged, meaning the surface monolayer components (phospholipids and unesterified cholesterol) are increased during fatty acid reesterification in the enterocyte [43]. Bolus feeding of lipids is known to increase the triglyceride portion of very lowdensity lipoproteins [44]. However, bolus feeding of lipids disturbs rumen function by altering biohydrogenation and reduces DMI. Litherland et al. [50] demonstrated that reductions in DMI may be more pronounced with unsaturated free fatty acids rather than unsaturated triglycerides reaching the duodenum as a result of feeding increased quantities of supplemental fat.

\section{Systemic lipid transport}

Unlike simple stomached animals, synthesis and secretion of very low-density lipoproteins by the bovine liver is minimal [44, 51]. This is related to the continuous flow of digesta in ruminants as opposed to the boluses associated with meals consumed by nonruminants. As triglyceride proportion diminishes, lipoprotein density increases and they contain greater concentrations of cholesterol esters, phospholipids and apolipoproteins. Intermediate-density lipoproteins and low-density lipoproteins are remnants of extensive very low-density lipoprotein triglyceride hydrolysis, but both classes have minimal concentration in the plasma of lactating cows [44]. High density lipoproteins are the major plasma lipoprotein in ruminants and are secreted by the liver as a reverse cholesterol transport system, returning excess peripheral cholesterol to the liver for bile secretion [44]. Rapid metabolism of very low-density lipoproteins (within $5 \mathrm{~min}$ ) during lactation is due to triglyceride hydrolysis, but the metabolic half-life of low-density lipoproteins and high-density lipoproteins is much greater
[49]. In fact, the fractional removal rate of very lowdensity lipoproteins is approximately 10 -fold greater than that of low-density lipoproteins [47]. Supporting this rapid turnover, the triglyceride component of very low-density lipoproteins is a precursor for milk fat synthesis in addition to plasma free fatty acids. Harvatine and Bauman [52] demonstrated a slight lag in conjugated linoleic acid enrichment of and clearance from plasma phospholipids compared to triglycerides with abomasal infusion. This lag in phospholipid clearance supports the decreased turnover rate for high-density lipoproteins compared to very low-density lipoproteins in plasma.

Although feeding supplemental polyunsaturated fatty acids can overwhelm the normal esterification capacity of the small intestine allowing increased incorporation of polyunsaturated fatty acids into triglycerides secreted from enterocytes [44], partitioning of polyunsaturated fatty acids into plasma lipid fractions that are less available to the mammary gland is more common [4]. Previous results have demonstrated that supplemental, very long-chain, n-3 fatty acids are primarily transported in the phospholipids or cholesterol ester fraction of blood, making them largely unavailable to the mammary gland for enrichment of milk fat [53-55]. Christie et al. [56] hypothesized selective hydrolysis of very low-density lipoproteins triglycerides at the liver may protect polyunsaturated fatty acids from nonessential functions. Mammary uptake of triglyceride fatty acids from plasma is dependent upon the action of mammary lipoprotein lipase on chylomicrons and very low-density lipoproteins $[46,57]$. The low transfer of polyunsaturated fatty acids to milk might be explained by the incorporation of polyunsaturated fatty acids into phospholipids and cholesterol esters at the small intestine or liver limiting their uptake by the mammary gland [58], although some data suggest that phospholipid fatty acids can contribute to the milk fatty acids [59-61].

Additionally, clearance of polyunsaturated fatty acids from triglycerides transported in very low-density lipoproteins may not occur via lipoprotein lipase. In studies utilizing triglyceride emulsions designed to model very low-density lipoproteins, the rate of clearance is fastest for fish oil emulsion particles, followed by medium-chain triglycerides and last, long-chain triglycerides emulsion particles [62]. Multiple pathways including lipoprotein lipase, apolipoprotein E, low-density lipoprotein receptor, and the lactoferrin-sensitive pathway control removal of longchain triglycerides from emulsions containing primarily n-6 fatty acids [63, 64]. Park et al. [65] proposed increased margination of $n$-3-rich particles reflected activation of lipoprotein lipase. Margination is particle attachment to endothelium-bound lipoprotein lipase during lipolysis. Qi et al. [63] then suggested lipoprotein lipase primarily 
functions as a "bridge" protein to mediate fatty acids uptake through membrane-anchoring. Removal of n-3 particles was less affected by this mechanism and independent of apolipoprotein E, low-density lipoproteins receptor, and lactoferrin. In fact, Murray-Taylor et al. [64] demonstrated that the uptake of n-3 emulsion particles depends upon cell surface proteoglycans and non-low-density lipoprotein receptor cell surface anchoring. These studies might suggest mammary uptake mechanisms present in the lactating dairy cow may conserve essential fatty acids by limiting uptake of $n-3$ polyunsaturated fatty acids.

\section{Intracellular fatty acid transport}

Following hydrolysis of triglycerides by mammary lipoprotein lipase, locally generated free fatty acids must cross the plasma membrane to enter the cell. There is considerable debate as to whether long-chain fatty acid transfer, especially in the case of polyunsaturated fatty acids, requires transport proteins or occurs through diffusion through the lipid bilayer. In nonruminants, rapidly facilitated protein-mediated uptake occurs through the fatty acid translocase/CD36 membrane receptor and fatty acid transport proteins, and CD36 is found in the milk fat globule membrane [66]. In adipocytes, the fatty acid translocase/CD36 complex is located within cavaeolae, flask-shaped lipid rafts rich in sphingolipids and cholesterol that create unique membrane domains [67]. The polyunsaturation of docosahexaenoic acid and its opposing interaction with sphingolipids and cholesterol cause it to disrupt lipid rafts [68]. It is possible that disruption of the size and distribution of lipid rafts by docosahexaenoic acid alters the ability of lipoprotein lipase to anchor very low-density lipoproteins for uptake of fatty acids by fatty acid translocase/CD36 or that the complex itself is disrupted. This might explain why transfer efficiencies for other n-3 polyunsaturated fatty acids, such as linolenic acid, resemble linoleic acid, another 18 carbon fatty acid.

As these long-chain fatty acids enter the cell, longchain acyl-CoA synthetases (ACSL) catalyze the synthesis of fatty acyl-CoA, the substrates for both catabolic and anabolic pathways in the cell. The predominant isoform in bovine mammary tissue is ACSL1, and it may have a role in milk fat synthesis [66]. These ACSL isoforms may have overlapping substrate specificity, but it is possible that tissue specific distribution of each isoform allows for regulation of fatty acid fate within the cell.

Intracellular fatty acid binding proteins (FABP) are cytoplasmic proteins that are hypothesized to be essential for fatty acid transport and metabolism within the cell by accelerating long-chain fatty acid uptake and targeting fatty acids to intracellular organelles. Fatty acid binding proteins are over 25 times more effective than albumin in increasing long-chain fatty acid solubility in the cytoplasm and may target transfer of long-chain fatty acids to acceptor membranes through direct membrane interaction [69]. Intracellular fatty acid trafficking is quite complex, and functional redundancy and cooperation exists among several proteins, including others such as ACSL and fatty acid transport proteins which also determine metabolic fates of long-chain fatty acids [70]. There are also distinct differences in the function and binding activity of the nine FABP isoforms identified [71].

A $15 \mathrm{kD}$ protein, FABP3 is highly expressed in cardiac and skeletal muscle, and has been linked to fatty acid trafficking, metabolism, and signaling. It was originally isolated in the mammary gland as the primary component of mammary-derived growth inhibitor as reviewed by Mather et al. [72]. Characterization of mammaryderived growth inhibitor revealed it to be a complex of FABP3 with some FABP4 [73-75]. The mammaryderived growth inhibitor complex inhibits cell proliferation in mammary epithelial cell lines in vitro and may play a role in the onset of differentiation $[75,76]$. These effects of FABP3 may be independent of its fatty acid binding effects. Clark et al. [77] determined FABP3 lacks an N-terminal signal peptide, and it is not known if the protein complex is secreted in vivo.

According to Bionaz and Loor $[66,78]$, temporal patterns of gene expression reveal that FABP3 and FABP4 are highly expressed in bovine mammary tissue during early lactation, which follows the temporal pattern of MDGI expression in lactation observed by Politis et al. [76]. Bionaz and Loor [78] proposed a role of FABP3 in channeling long-chain fatty acids to stearoyl-CoA desaturase or triacylglycerol synthesis or in long-chain fatty acids activation of gene expression through peroxisome proliferator activated receptor- $\gamma$. Deletion of the FABP3 gene in mice causes defective fatty acid oxidation compensated by increased glucose utilization in heart and skeletal muscle [71]. While Clark et al. [77] reported no overt effects of gene deletion on mammary gland phenotype, FABP3 null mice appeared to have a lower percentage of total unsaturated fatty acids in milk fat. Overexpression bovine FABP3 in the non-secretory bovine mammary epithelial cell line, MAC-T, did not influence cellular fatty acid composition (Stamey and Corl, unpublished results). The human breast cancer cell line MCF7 does not express FABP3 and overexpression of FABP3 in MCF7 cells increased uptake of radioactively labeled palmitate and oleate, but other changes in fatty acid metabolism were not observed [79]. Kadegowda et al. [80] reported FABP3 expression increased in MAC-T cells when treated with rosiglitazone to activate proliferator activated receptor- $\gamma$ and palmitate or stearate. Together, these findings support a potential role for FABP3 and FABP4 in lipid synthesis in the bovine mammary gland though the exact biological function remains to be elucidated. 


\section{Milk fat synthesis}

Both preformed fatty acids from plasma and de novo synthesized fatty acids in the mammary epithelial cell contribute to milk fat [57]. Polyunsaturated fatty acids in milk fat are derived from the preformed fatty acids in plasma. Preformed fatty acids arise from free fatty acids mobilized from adipose tissue or from dietary fatty acids transported in the triglyceride portion of very lowdensity lipoproteins. Acetate serves as the primary substrate for de novo lipogenesis and is converted to malonyl-CoA by acetyl-CoA carboxylase and is chainelongated by fatty acid synthase catalyzing the addition of volatile fatty acids [81]. In adipose tissues, fatty acids are elongated to 16 carbons, forming palmitate, but in the mammary gland, short-chain fatty acids are rapidly released for esterification into triglycerides prior to complete elongation by chain-terminating transacylation by fatty acid synthase [82]. Saturated, long-chain fatty acids are shuttled to stearoyl-CoA desaturase, which inserts a double bond at the ninth position from the carboxyl end [57]. Other, non-saturated substrates can also be used by stearoyl-CoA desaturase including several trans 18:1 isomers [83]. Two trans 18:1 isomers, trans- 11 and trans-7 18:1, produce conjugated linoleic acid isomers when desaturated at the ninth carbon [84, 83].

Preformed, de novo, and desaturated fatty acids are all delivered to the endoplasmic reticulum where they are esterified into triglycerides via the glycerol-3-phosphate pathway. As reviewed by Coleman and Mashek [85], glycerol-3-phosphate is converted to lysophosphatidic acid by glycerol-3-phosphate acyltransferase, adding a fatty acyl-CoA at the $s n-1$ position. Lysophosphatidic acid is converted to phosphatidic acid via acylation of the $s n-2$ position by acylglycerophosphate acyltransferase. Phosphatidic acid is a key intermediate in lipid synthesis as it is a branch point for phospholipid and triacylglycerol synthesis [85]. Multiple isoforms of acylglycerophosphate acyltransferase exist, and it is likely each isoform has specificity for incorporation of specific fatty acids in the $s n-2$ position. With the addition of another fatty acyl-CoA, phosphatidic acid is converted to diacylglycerol by phosphatidic acid phosphohydrolase.

To produce a triglyceride, the final fatty acyl-CoA, usually a short-chain fatty acid [86], is added by diacylglycerol acyltransferase. A single nucleotide polymorphism in diacylglycerol acyltransferase 1 in the mammary gland allows for genetic selection of cattle with enhanced milk fat yield [87]. Triglycerides accumulate within lipid droplets in the cell, which may contain portions of the rough ER, and gradually migrate to the apical plasma membrane of the mammary epithelial cell where they bud off with the plasma membrane forming the milk fat globule membrane [88].

\section{Transgenic approach to increasing milk fat polyunsaturated fatty acids}

The limitations so far presented for transfer of polyunsaturated fatty acids, especially those of the n-3 series, into milk fat and the era of transgenics offer new approaches to alter milk fatty acid composition. The location of double bonds within the carbon backbone of polyunsaturated fatty acids makes them essential in the diet because mammals lack desaturase enzymes capable of adding double bonds beyond the ninth carbon. The only member of the animal kingdom known to include the delta-15 desaturase gene is the nematode, Caenorhabditis elegans. In recent years, efforts to incorporate this gene into the genome of mammals with expression specific to the mammary gland has been used to increase n-3 fatty acids in milk fat of mice [89]. Transgene expression was largely isolated to the mammary gland through the use of the $\beta$-casein gene promoter, although some expression was found in muscle also. Milk fat was separated into phospholipid and triacylglycerol fractions for fatty acid analysis and the greatest changes in polyunsaturated fatty acids were found in the phospholipid fraction. Significant increases linolenic and eicosapentaenoic were observed in both phospholipid and triacylglycerol fractions. Concomitant reductions in linoleic and arachidonic acids were observed in the phospholipid fraction. In a separate report, increases in n-3 docosapentaenoic acid in the triacylglycerol fraction and docosahexaenoic acid in the phospholipid fraction were observed [90]. Phospholipids make up a small fraction of milk fat and the presence of $n-3$ enrichment in this milk fat fraction limits overall changes in milk fatty acid composition. The enhanced localization of n-3 polyunsaturated fatty acid enrichment to the phospholipid fraction might be explained by substrate preference of the C. elegans desaturase for acyl lipids [91]. Despite the potentially low total enrichment of milk fat with n-3 polyunsaturated fatty acids, pups consuming the milk of transgenic dams had significantly enriched $n-3$ polyunsaturated fatty acids in brain lipids [90, 92].

There is now a report of a transgenic cow expressing the $C$. elegans desaturase [93]. To date, only the results for one cow are published. The chicken $\beta$-actin promoter was included allowing expression of the desaturase gene outside the mammary gland. Comparison with a cloned cow not expressing the transgene revealed increases in $\mathrm{n}-3$ fatty acid content of milk fat and reductions in the $\mathrm{n}-6$ series, but authors did not report overall milk fatty acid composition [93] and so it is difficult to determine the overall content of n-3 and n- 6 fatty acids in milk fat. As the fatty acid substrate for the desaturase gene is linoleic acid and all polyunsaturated fatty acids are low in milk fat, the enrichment of n-3 fatty acids is likely limited by the availability of the substrate. 


\section{Conclusions}

Increasing polyunsaturated fatty acids in the milk fat of lactating dairy cattle is very challenging. The cow has multiple mechanisms capable of thwarting efforts to enrich milk fat with polyunsaturated fatty acids. Research into the mechanisms of rumen biohydrogenation, fatty acid digestion and absorption by the small intestine, and uptake and trafficking by the mammary epithelial cells of the lactating dairy cow has shed light on the obstacles that erode the effectiveness of simple supplementation strategies. These challenges have created an active area of research in the last half-century, increasingly motivated by consumer demand for healthier food choices. The more recent efforts at transgenic manipulation to bypass the evolutionarily engrained mechanisms of the cow might have potential to increase the polyunsaturated fatty acid content of milk fat, but even they present challenges not the least of which is the largely untested consumer tolerance for food from transgenic animals.

\section{Competing interests}

The authors declare that they have no competing interests.

\section{Authors' contributions}

Both authors drafted the manuscript together and approved the final version.

\section{Acknowledgements}

Funding for this work was provided in part, by the Virginia Agricultural Experiment Station and the Hatch Program of the National Institute of Food and Agriculture, U.S. Department of Agriculture.

\section{Author details}

'Phibro Animal Health Corporation, Teaneck, NJ, USA. ${ }^{2}$ Department of Dairy Science, Virginia Tech, Blacksburg, VA 24061-0315, USA.

Received: 27 January 2015 Accepted: 2 June 2015

Published online: 12 June 2015

\section{References}

1. Jenkins TC, McGuire MA. Major advances in nutrition: Impact on milk composition. J Dairy Sci. 2006;89(4):1302-10. doi:10.3168/jds.S00220302(06)72198-1.

2. Kelm SC, Freeman AE. Direct and correlated responses to selection for milk yield: results and conclusions of regional project NC-2, "improvement of dairy cattle through breeding, with emphasis on selection". NC-2 Technical Committee. J Dairy Sci. 2000;83(12):2721-32.

3. Kay JK, Weber WJ, Moore CE, Bauman DE, Hansen LB, Chester-Jones H, et al. Effects of week of lactation and genetic selection for milk yield on milk fatty acid composition in Holstein cows. J Dairy Sci. 2005;88(11):3886-93. doi:10.3168/jds.S0022-0302(05)73074-5.

4. Lock AL, Bauman DE. Modifying milk fat composition of dairy cows to enhance fatty acids beneficial to human health. Lipids. 2004;39(12):1197-206.

5. Naik PK. Bypass fat in dairy ration - a review. Anim Nutr Feed Technol. 2013;13(1):147-63.

6. Broun P, Gettner S, Somerville C. Genetic engineering of plant lipids. Annu Rev Nutr. 1999;19:197-216. doi:10.1146/annurev.nutr.19.1.197.

7. Hazebroek JP. Analysis of genetically modified oils. Prog Lipid Res. 2000;39(6):477-506.

8. Drackley JK. Interorgan lipid and fatty acid metabolism in growing ruminants. In: Burrin DG, Mersmann HJ, editors. Biology of Metabolism in Growing Animals. Biology of Growing Animals. New York: Elsevier Ltd; 2005. p. 323-50.

9. Loor JJ, Ueda K, Ferlay A, Chilliard Y, Doreau M. Biohydrogenation, duodenal flow, and intestinal digestibility of trans fatty acids and conjugated linoleic acids in response to dietary forage:concentrate ratio and linseed oil in dairy cows. J Dairy Sci. 2004;87(8):2472-85. doi:10.3168/jds.S0022-0302(04)73372-X.

10. Kalscheur KF, Teter BB, Piperova LS, Erdman RA. Effect of fat source on duodenal flow of trans-C18:1 fatty acids and milk fat production in dairy cows. J Dairy Sci. 1997;80(9):2115-26. doi:10.3168/jds.S0022-0302(97)76157-5.

11. Kalscheur KF, Teter BB, Piperova LS, Erdman RA. Effect of dietary forage concentration and buffer addition on duodenal flow of trans-C18:1 fatty acids and milk fat production in dairy cows. J Dairy Sci. 1997;80(9):2104-14. doi:10.3168/jds.S0022-0302(97)76156-3.

12. Dawson RM, Hemington N, Hazlewood GP. On the role of higher plant and microbial lipases in the ruminal hydrolysis of grass lipids. Br J Nutr. 1977;38(2):225-32. doi:10.1079/bjn19770082.

13. Hawke JC, Silcock WR. Lipolysis and hydrogenation in the rumen. Biochem J. 1969;112(1):131-2.

14. Kepler CR, Tucker WP, Tove SB. Biohydrogenation of unsaturated fatty acids. IV. Substrate specificity and inhibition of linoleate delta-12-cis, delta-11trans-isomerase from Butyrivibrio fibrisolvens. J Biol Chem. 1970;245(14):3612-20.

15. Van Nevel CJ, Demeyer DI. Influence of pH on lipolysis and biohydrogenation of soybean oil by rumen contents in vitro. Reprod Nutr Dev. 1996;36(1):53-63.

16. Hazlewood GP, Kemp P, Lander D, Dawson RMC. C-18 unsaturated fatty acid hydrogenation patterns of some rumen bacteria and their ability to hydrolyze exogenous phospholipid. Br J Nutr. 1976;35(2):293-7. doi:10.1079/ bjn19760034.

17. Singh S, Hawke JC. The in vitro lipolysis and biohydrogenation of monogalactosyldiglyceride by whole rumen contents and its fractions. I Sci Food Agric. 1979;30(6):603-12.

18. Harfoot CG, Hazlewood GP. Lipid metabolism in the rumen. In: Hobson PN, editor. The Rumen Microbial Ecosystem. London: Elsevier Applied Science Publishers; 1988. p. 285-322.

19. Polan CE, MC Neill JJ, Tove SB. Biohydrogenation of unsaturated fatty acids by rumen bacteria. J Bacteriol. 1964;88(4):1056-64.

20. Kemp P, Lander DJ. Hydrogenation in vitro of a-linolenic acid to stearic acid by mixed cultures of pure strains of rumen bacteria. J Gen Micro. 1984;130(MAR):527-33.

21. Lourenco M, Ramos-Morales E, Wallace RJ. The role of microbes in rumen lipolysis and biohydrogenation and their manipulation. Animal. 2010;4(7):1008-23. doi:10.1017/S175173111000042x.

22. Yokoyama MT, Davis CL. Hydrogenation of unsaturated fatty acids by Treponema (Borrelia) strain B 25 , a rumen spirochete. J Bacteriol. 1971;107(2):519-27.

23. Kepler CR, Tove SB. Biohydrogenation of unsaturated fatty acids. 3 . Purification and properties of a linoleate delta-12-cis, delta-11-trans-isomerase from Butyrivibrio fibrisolvens. J Biol Chem. 1967;242(24):5686-92.

24. Davis C, Brown R, editors. Low-fat milk syndrome. Physiology of digestion and metabolism in the ruminant. Proceedings of the third international symposium, Cambridge, England; August 1969.; 1970: Newcastle-upon-Tyne: Oriel Press.

25. Griinari JM, Dwyer DA, McGuire MA, Bauman DE, Palmquist DL, Nurmela KV. Trans-octadecenoic acids and milk fat depression in lactating dairy cows. J Dairy Sci. 1998;81(5):1251-61. doi:10.3168/jds.S0022-0302(98)75686-3.

26. Bauman DE, Griinari JM. Nutritional regulation of milk fat synthesis. Annu Rev Nutr. 2003;23:203-27. doi:10.1146/annurev.nutr.23.011702.073408.

27. Jenkins TC, Wallace RJ, Moate PJ, Mosley EE. Board-invited review: recent advances in biohydrogenation of unsaturated fatty acids within the rumen microbial ecosystem. J Anim Sci. 2008;86(2):397-412. doi:10.2527/jas.2007-0588.

28. Baumgard LH, Corl BA, Dwyer DA, Saebo A, Bauman DE. Identification of the conjugated linoleic acid isomer that inhibits milk fat synthesis. Am J Physiol Regul Integr Comp Physiol. 2000;278(1):R179-84.

29. Peterson DG, Baumgard LH, Bauman DE. Short communication: milk fat response to low doses of tran-10, cis-12 conjugated linoleic acid (CLA). J Dairy Sci. 2002;85(7):1764-6.

30. Lock AL, Tyburczy C, Dwyer DA, Harvatine KJ, Destaillats F, Mouloungui Z, et al. Trans-10 octadecenoic acid does not reduce milk fat synthesis in dairy cows. J Nutr. 2007;137(1):71-6.

31. Klein CM, Jenkins TC. Docosahexaenoic acid elevates trans-18:1 isomers but is not directly converted into trans-18:1 isomers in ruminal batch cultures. J Dairy Sci. 2011;94(9):4676-83. doi:10.3168/jds.2011-4344.

32. AbuGhazaleh AA, Jenkins TC. Short communication: docosahexaenoic acid promotes vaccenic acid accumulation in mixed ruminal cultures when 
incubated with linoleic acid. J Dairy Sci. 2004;87(4):1047-50. doi:10.3168/ jds.S0022-0302(04)73250-6.

33. Whitlock LA, Schingoethe DJ, AbuGhazaleh AA, Hippen AR, Kalscheur KF. Milk production and composition from cows fed small amounts of fish oil with extruded soybeans. J Dairy Sci. 2006;89(10):3972-80. doi:10.3168/ jds.50022-0302(06)72440-7.

34. Whitlock LA, Schingoethe DJ, Hippen AR, Kalscheur KF, Baer RJ, Ramaswamy $\mathrm{N}$, et al. Fish oil and extruded soybeans fed in combination increase conjugated linoleic acids in milk of dairy cows more than when fed separately. J Dairy Sci. 2002:85(1):234-43. doi:10.3168/jds.500220302(02)74072-1.

35. Santos JE, Bilby TR, Thatcher WW, Staples CR, Silvestre FT. Long chain fatty acids of diet as factors influencing reproduction in cattle. Reprod Domest Anim. 2008;43 Suppl 2:23-30. doi:10.1111/j.1439-0531.2008.01139.x.

36. Mattos R, Staples CR, Arteche A, Wiltbank MC, Diaz FJ, Jenkins TC, et al. The effects of feeding fish oil on uterine secretion of PGF2alpha, milk composition, and metabolic status of periparturient Holstein cows. J Dairy Sci. 2004;87(4):921-32. doi:10.3168/jds.50022-0302(04)73236-1.

37. Mattos R, Staples CR, Thatcher WW. Effects of dietary fatty acids on reproduction in ruminants. Rev Reprod. 2000;5(1):38-45.

38. Staples CR, Burke JM, Thatcher WW. Influence of supplemental fats on reproductive tissues and performance of lactating cows. J Dairy Sci. 1998;81(3):856-71. doi:10.3168/jds.S0022-0302(98)75644-9.

39. Jenkins TC, Bridges WC. Protection of fatty acids against ruminal biohydrogenation in cattle. Eur J Lipid Sci Tech. 2007;109(8):778-89. doi:10.1002/ejlt.200700022.

40. Castaneda-Gutierrez E, de Veth MJ, Lock AL, Dwyer DA, Murphy KD, Bauman DE. Effect of supplementation with calcium salts of fish oil on $n-3$ fatty acids in milk fat. J Dairy Sci. 2007;90(9):4149-56. doi:10.3168/jds.2006-856.

41. Perfield 2nd JW, Lock AL, Pfeiffer AM, Bauman DE. Effects of amideprotected and lipid-encapsulated conjugated linoleic acid supplements on milk fat synthesis. J Dairy Sci. 2004;87(9):3010-6.

42. Stamey JA, Shepherd DM, de Veth MJ, Corl BA. Use of algae or algal oil rich in $\mathrm{n}-3$ fatty acids as a feed supplement for dairy cattle. J Dairy Sci. 2012;95(9):5269-75. doi:10.3168/jds.2012-5412.

43. Noble RC. Digestion, absorption and transport of lipids in ruminant animals. Prog Lipid Res. 1978;17(1):55-91.

44. Bauchart D. Lipid absorption and transport in ruminants. J Dairy Sci. 1993;76(12):3864-81. doi:10.3168/jds.S0022-0302(93)77728-0.

45. Jenkins TC. Lipid metabolism in the rumen. J Dairy Sci. 1993;76(12):3851-63. doi:10.3168/jds.S0022-0302(93)77727-9.

46. Palmquist DL. A kinetic concepto of lipid transport in ruminants. J Dairy Sci. 1976;59(3):355-63.

47. Palmquist DL, Mattos W. Turnover of lipoproteins and transfer to milk fat of dietary (1-Carbon-14) linoleic acid in lactating cows. J Dairy Sci. 1978;61(5):561-5.

48. Emery RS. Deposition, secretion, transport and oxidation of fat in ruminants. J Anim Sci. 1979;48(6):1530-7.

49. Raphael BC, Dimick PS, Puppione DL. Lipid characterization of bovine serum lipoproteins throughout gestation and lactation. J Dairy Sci. 1973;56(8):1025-32. doi:10.3168/jds.50022-0302(73)85300-7.

50. Litherland NB, Thire S, Beaulieu AD, Reynolds CK, Benson JA, Drackley JK. Dry matter intake is decreased more by abomasal infusion of unsaturated free fatty acids than by unsaturated triglycerides. J Dairy Sci. 2005;88(2):632-43. doi:10.3168/jds.S0022-0302(05)72727-2.

51. Drackley JK. ADSA Foundation Scholar Award. Biology of dairy cows during the transition period: the final frontier? J Dairy Sci. 1999;82(11):2259-73.

52. Harvatine KJ, Bauman DE. Characterization of the acute lactational response to trans-10, cis-12 conjugated linoleic acid. J Dairy Sci. 2011;94(12):6047-56. doi:10.3168/jds.2011-4657.

53. Brumby PE, Storry JE, Sutton JD. Metabolism of cod-liver oil in relation to milk fat secretion. J Dairy Res. 1972;39(1):167-82.

54. Kitessa SM, Gulati SK, Ashes JR, Fleck E, Scott TW, Nichols PD. Utilisation of fish oil in ruminants - I. Fish oil metabolism in sheep. Anim Feed Sci Tech. 2001;89(3-4):189-99. doi:10.1016/s0377-8401(00)00233-9.

55. Offer NW, Speake BK, Dixon J, Marsden M. Effect of fish-oil supplementation on levels of $(n-3)$ poly-unsaturated fatty acids in the lipoprotein fractions of bovine plasma. Animal Science. 2001;73:523-31.

56. Christie WW, Noble RC, Clegg RA. The hydrolysis of very low density lipoproteins and chylomicrons of intestinal origin by lipoprotein lipase in ruminants. Lipids. 1986;21(3):252-3.
57. Moore $\mathrm{JH}$, Christie WW. Lipid metabolism in the mammary gland of ruminant animals. Prog Lipid Res. 1979;17(4):347-95.

58. Mansbridge RJ, Blake JS. Nutritional factors affecting the fatty acid composition of bovine milk. Br J Nutr. 1997;78 Suppl 1:S37-47.

59. Mosley EE, Shafii Dagger B, Moate PJ, McGuire MA. cis-9, trans-11 conjugated linoleic acid is synthesized directly from vaccenic acid in lactating dairy cattle. J Nutr. 2006;136(3):570-5.

60. Loor JJ, Quinlan LE, Bandara ABPA, Herbein JH. Distribution of transvaccenic acid and cis9,trans11-conjugated linoleic acid (rumenic acid) in blood plasma lipid fractions and secretion in milk fat of Jersey cows fed canola or soybean oil. Animal Research. 2002;51(2):119-34. doi:10.1051/ animres:2002013.

61. Nielsen MO, Jakobsen K. Changes in mammary uptake of free fatty acids, triglyceride, cholesterol and phospholipid in relation to milk synthesis during lactation in goats. Comp Biochem Physiol A Physiol. 1994;109(4):857-67.

62. Qi K, Seo T, Al-Haideri M, Worgall TS, Vogel T, Carpentier YA, et al. Omega-3 triglycerides modify blood clearance and tissue targeting pathways of lipid emulsions. Biochemistry. 2002:41(9):3119-27.

63. Qi K, Seo T, Jiang Z, Carpentier YA, Deckelbaum RJ. Triglycerides in fish oil affect the blood clearance of lipid emulsions containing long- and mediumchain triglycerides in mice. J Nutr. 2006;136(11):2766-72.

64. Murray-Taylor FM, Ho YY, Densupsoontorn N, Chang CL, Deckelbaum RJ, Seo T. n-3, but not $n-6$ lipid particle uptake requires cell surface anchoring. Biochem Biophys Res Commun. 2010;392(2):135-9. doi:10.1016/j.bbrc. 2009.12.164

65. Park Y, Jones PG, Harris WS. Triacylglycerol-rich lipoprotein margination: a potential surrogate for whole-body lipoprotein lipase activity and effects of eicosapentaenoic and docosahexaenoic acids. Am J Clin Nutr. 2004;80(1):45-50.

66. Bionaz $\mathrm{M}$, Loor JJ. Gene networks driving bovine milk fat synthesis during the lactation cycle. Bmc Genomics. 2008;9:366. doi:10.1186/1471-2164-9-366.

67. Pohl J, Ring A, Korkmaz U, Ehehalt R, Stremmel W. FAT/CD36-mediated long-chain fatty acid uptake in adipocytes requires plasma membrane rafts. Mol Biol Cell. 2005;16(1):24-31. doi:10.1091/mbc.E04-07-0616.

68. Chapkin RS, McMurray DN, Davidson LA, Patil BS, Fan YY, Lupton JR. Bioactive dietary long-chain fatty acids: emerging mechanisms of action. $\mathrm{Br}$ J Nutr. 2008;100(6):1152-7. doi:10.1017/s0007114508992576.

69. McArthur MJ, Atshaves BP, Frolov A, Foxworth WD, Kier AB, Schroeder F. Cellular uptake and intracellular trafficking of long chain fatty acids. J Lipid Res. 1999;40(8):1371-83.

70. Sandoval A, Fraisl P, Arias-Barrau E, Dirusso CC, Singer D, Sealls W, et al. Fatty acid transport and activation and the expression patterns of genes involved in fatty acid trafficking. Arch Biochem Biophys. 2008;477(2):363-71. doi:10.1016/j.abb.2008.06.010.

71. Storch J, Corsico B. The emerging functions and mechanisms of mammalian fatty acid-binding proteins. Annu Rev Nutr. 2008;28:73-95. doi:10.1146/annurev.nutr.27.061406.093710.

72. Mather $\mathrm{IH}$. A review and proposed nomenclature for major proteins of the milk-fat globule membrane. J Dairy Sci. 2000;83(2):203-47. doi:10.3168/ jds.S0022-0302(00)74870-3.

73. Specht B, Bartetzko N, Hohoff C, Kuhl H, Franke R, Borchers T, et al. Mammary derived growth inhibitor is not a distinct protein but a mix of heart-type and adipocyte-type fatty acid-binding protein. J Biol Chem. 1996;271(33):19943-9.

74. Spener F, Unterberg C, Borchers T, Grosse R. Characteristics of fatty acidbinding proteins and their relation to mammary-derived growth inhibitor. Mol Cell Biochem. 1990;98(1-2):57-68.

75. Yang Y, Spitzer E, Kenney N, Zschiesche W, Li M, Kromminga A, et al. Members of the fatty acid binding protein family are differentiation factors for the mammary gland. J Cell Biol. 1994;127(4):1097-109.

76. Politis I, Gorewit RC, Muller T, Grosse R. Mammary-derived growth inhibitor protein and messenger ribonucleic acid concentrations in different physiological states of the gland. J Dairy Sci. 1992;75(6):1423-9. doi:10.3168/ jds.S0022-0302(92)77896-5.

77. Clark AJ, Neil C, Gusterson B, McWhir J, Binas B. Deletion of the gene encoding $\mathrm{H}-\mathrm{FABP} / \mathrm{MDG}$ has no overt effects in the mammary gland. Transgenic Res. 2000;9(6):439-44.

78. Bionaz M, Loor JJ. ACSL1, AGPAT6, FABP3, LPIN1, and SLC27A6 are the most abundant isoforms in bovine mammary tissue and their expression is affected by stage of lactation. J Nutr. 2008;138(6):1019-24. 
79. Buhlmann C, Borchers T, Pollak M, Spener F. Fatty acid metabolism in human breast cancer cells (MCF7) transfected with heart-type fatty acid binding protein. Mol Cell Biochem. 1999;199(1-2):41-8.

80. Kadegowda AK, Bionaz M, Piperova LS, Erdman RA, Loor JJ. Peroxisome proliferator-activated receptor-gamma activation and long-chain fatty acids alter lipogenic gene networks in bovine mammary epithelial cells to various extents. J Dairy Sci. 2009;92(9):4276-89. doi:10.3168/jds.2008-1932.

81. Chilliard Y, Ferlay A, Mansbridge RM, Doreau M. Ruminant milk fat plasticity: nutritional control of saturated, polyunsaturated, trans and conjugated fatty acids. Annales De Zootechnie. 2000;49(3):181-205.

82. Knudsen J, Grunnet I. Transacylation as a chain-termination mechanism in fatty acid synthesis by mammalian fatty acid synthetase. Synthesis of medium-chain-length (C8-C12) acyl-CoA esters by goat mammary-gland fatty acid synthetase. Biochem J. 1982;202(1):139-43.

83. Griinari JM, Corl BA, Lacy SH, Chouinard PY, Nurmela KV, Bauman DE. Conjugated linoleic acid is synthesized endogenously in lactating dairy cows by Delta(9)-desaturase. J Nutr. 2000;130(9):2285-91.

84. Corl BA, Baumgard LH, Griinari JM, Delmonte P, Morehouse KM, Yurawecz MP, et al. Trans-7, cis-9 CLA is synthesized endogenously by delta9desaturase in dairy cows. Lipids. 2002;37(7):681-8.

85. Coleman RA, Mashek DG. Mammalian triacylglycerol metabolism: synthesis, lipolysis, and signaling. Chem Rev. 2011;111(10):6359-86. doi:10.1021/ cr100404w.

86. Breckenridge WC, Kuksis A. Structure of bovine milk fat triglycerides. II. Long chain lengths. Lipids. 1969;4(3):197-204.

87. Grisart B, Farnir F, Karim L, Cambisano N, Kim JJ, Kvasz A, et al. Genetic and functional confirmation of the causality of the DGAT1 K232A quantitative trait nucleotide in affecting milk yield and composition. Proc Natl Acad Sci U S A. 2004;101(8):2398-403.

88. Bauman DE, Mather IH, Wall RJ, Lock AL. Major advances associated with the biosynthesis of milk. J Dairy Sci. 2006;89(4):1235-43. doi:10.3168/ jds.S0022-0302(06)72192-0.

89. Kao BT, Lewis KA, DePeters EJ, Van Eenennaam AL. Endogenous production and elevated levels of long-chain n-3 fatty acids in the milk of transgenic mice. J Dairy Sci. 2006;89(8):3195-201. doi:10.3168/jds.S0022-0302(06)72594-2.

90. Kao BT, DePeters EJ, Van Eenennaam AL. Mice raised on milk transgenically enriched with n-3 PUFA have increased brain docosahexaenoic acid. Lipids. 2006;41(6):543-9.

91. Watts JL, Browse J. Genetic dissection of polyunsaturated fatty acid synthesis in Caenorhabditis elegans. Proc Natl Acad Sci U S A. 2002;99(9):5854-9. doi:10.1073/pnas.092064799.

92. Bongiovanni KD, Depeters EJ, Van Eenennaam AL. Neonatal growth rate and development of mice raised on milk transgenically enriched with omega-3 fatty acids. Pediatr Res. 2007;62(4):412-6. doi:10.1203/PDR. Ob013e31813cbeea.

93. Wu X, Ouyang H, Duan B, Pang D, Zhang L, Yuan T, et al. Production of cloned transgenic cow expressing omega-3 fatty acids. Transgenic Res. 2012;21(3):537-43. doi:10.1007/s11248-011-9554-2.

\section{Submit your next manuscript to BioMed Central and take full advantage of:}

- Convenient online submission

- Thorough peer review

- No space constraints or color figure charges

- Immediate publication on acceptance

- Inclusion in PubMed, CAS, Scopus and Google Scholar

- Research which is freely available for redistribution 